\title{
REPARO DE ESÔFAGO CERVICAL DE CÃES COM SEGMENTO INTESTINAL LIVRE AUTÓLOGO DESPROVIDO DE EPITÉLIO E DE LÂMINA PRÓPRIA DA TÚNICA MUCOSA. ${ }^{1}$
}

\author{
CANINE CERVICAL ESOPHAGUS REPAIR USING OF FREE AUTOGRAFT \\ INTESTINAL SEGMENT WITHOUT EPITHELIUM AND LAMINA \\ PROPRIA OF THE MUCOSA
}

\author{
Patrícia Maria Coletto Freitas ${ }^{2}$ Duvaldo Eurides ${ }^{3}$ Marcelo Emilio Beletti ${ }^{4}$ \\ Francisco Cláudio Dantas Mota ${ }^{2}$ Bianca Jacob Shimizu ${ }^{2}$ Elisete de Araújo Naves ${ }^{5}$ \\ Karen Silva Rebouças $^{6}$ Luiz Antônio Franco da Silva ${ }^{7}$ Maria Clorinda Soares Fioravanti ${ }^{7}$
}

RESUMO

Doze cães foram separados em dois grupos de igual número e submetidos à remoção de um retalho de $3,0 \times 3,5 \mathrm{~cm}$ do esôfago cervical. A abertura foi ocluída com enxerto de segmento intestinal livre autólogo desprovido de epitélio e lâmina própria da túnica mucosa, com pontos simples separados por fio poliglactina 910. Os animais do grupo 1 foram observados durante 15 dias de pós-operatório, e os do grupo 2, durante 30 dias. Observou-se epitelização e discreta estenose no local do enxerto com invasão de tecido conjuntivo denso rico em fibras colágenas. O enxerto de segmento intestinal livre autólogo foi eficiente no reparo de rupturas do esôfago cervical de cães.

Palavras-chave: cão, intestino, enxerto, cirurgia.

SUMMARY

Twelve dogs were allocated in two groups with same number of animals and submitted to removal of a $3.0 \times 3.5 \mathrm{~cm}$ piece of the cervical esophagus. The incision was occluded with a autograft of free intestinal segment without epithelium and lamina propria of the mисоsa, with separate simples points using poliglactina 910 line. Animals of the group 1 were observed for 15 days post-surgery, and the animals from group 2, for 30 days. Epithelization and discreet stenosis in the place of the graft with invasion of dense conjunctive tissue, rich in collagen fibers was noticed. The autograft free intestinal segment was efficient in the repair of ruptures in the cervical segment of the canine esophagous.

Key words: dog, intestinal, graft, surgery.

\section{INTRODUÇÃO}

As patologias do esôfago canino como as lacerações e / ou perda tecidual (QUESSADA $\boldsymbol{e t}$ al., 1986) e neoplasias (PARKER \& CAYWOOD, 1987) podem promover alterações obstrutivas.

\footnotetext{
${ }^{1}$ Trabalho executado com auxilio financeiro da Fundação de Amparo à Pesquisa do Estado de Minas Gerais (FAPEMIG).

${ }^{2}$ Médico Veterinário, Aluno do Programa de Mestrado em Ciências Veterinária-Clínica e Cirurgia, Faculdade de Medicina Veterinária (FAMEV), Universidade Federal de Uberlândia (UFU).

${ }^{3}$ Médico Veterinário, Professor titular, Doutor, FAMEV, UFU. Av. Pará 1720, Campus Umuarama, 38400-902, Uberlândia, MG. Brasil.

E-mail: duvaldo@ufu.br. Autor para correspondência.

${ }^{4}$ Médico Veterinário, Professor Adjunto, Doutor, Departamento de Morfologia, UFU.

${ }^{5}$ Médico Veterinário, Zoológico de Uberlândia, MG.

${ }^{6}$ Acadêmica, Faculdade de Medicina Veterinária, Universidade Federal da Bahia.

${ }^{7}$ Médico Veterinário, Professor Adjunto, Doutor, Escola de Veterinária, Universidade Federal de Goiás.
} 
Diversos fatores podem ocasionar resultados indesejáveis nas reparações esofágicas. Alguns independem da qualidade do ato operatório, por serem inerentes à própria constituição anátomofisiológica do órgão, como a ausência da camada serosa (PEACOCK \& VAN WINKLE, 1976; PARKER \& CAYWOOD, 1987), suprimento sangüíneo deficiente (PEACOCK \& VAN WINKLE, 1976), movimentação esofágica (CHEN et al., 1987), incapacidade do músculo esofágico de suportar pontos de suturas (FREEMAN, 1982); pouca tolerância à tensão e distensão longitudinal (HOFFER, 1985), ausência de omento que protege de aderências (PARKER \& CAYWOOD, 1987), posição anatômica do órgão (PEACOCK \& VAN WINKLE, 1976) e debilidade do paciente (HOFFER, 1985).

As anastomoses término-terminal são as melhores soluções nas aproximações dos cotos. No entanto, podem apresentar dificuldades que exigem outras opções para resolvê-las (NIGRO, 1996). Uma ressecção do esôfago maior de $3,0 \mathrm{~cm}$ de comprimento impossibilita a anastomose por exigir alongamento esofágico (BRIGHT, 1998).

Diversos biomateriais foram utilizados para reparo de alterações do esôfago de cães como pele (FRIEDMAN et al., 1988), pericárdio (PARKER \& CAYWOOD, 1987), fáscia lata sobre malha de tântalo (Baronofsky \& Hilger apud LYONS et al., 1962), peritônio de cães (DALECK et $\boldsymbol{a l}$., 1988), retalho de músculo esternomastóideo (CONTESINI et al., 1992b), vicryl (CARACHI $\boldsymbol{e t}$ al., 1989), polietileno (LYONS et al., 1962), borracha, malha de aço inoxidável e malha de dacron (LYONS et al., 1962), tubo de silicone (CONTESINI et al., 1992a), intestino delgado (PEACOCK \& VAN WINKLE, 1976; PARKER \& CAYWOOD, 1987; CHEN et al., 1987) e estômago (PEACOCK \& VAN WINKLE, 1976). HERMERECK \& CRAWFORD (1976) analisaram criticamente seus resultados e verificaram que nas esofagocoloplastias, houve fístula em $42 \%$ dos casos e nas esofagogastropatias em 17,8\%. As deiscências das anastomoses esofágicas foram responsáveis por $54 \%$ dos óbitos das casuísticas desses autores. ZILBERSTEN et al. (1987) referiram que, apesar dos vários tipos de implantes realizados no esôfago cervical, o segmento de intestino delgado é indicado devido à melhor adequação de calibre e facilidade de ressecção. De acordo com HAMNER et al. (1955), após um ano da restituição do esôfago por segmento intestinal, o local do enxerto encontrava-se em condições satisfatórias.

No presente experimento, foi proposto um método de correção de defeitos provocados em esôfago cervical de cães com enxerto autólogo de segmento do jejuno livre desprovido de epitélio e lâmina própria de túnica mucosa.

\section{MATERIAL E MÉTODOS}

Foram utilizados 12 cães, machos e fêmeas adultos, sem raça definida, com peso variando de 5 a $15 \mathrm{~kg}$. Os animais foram separados em dois grupos de igual número. Os do grupo 1 foram submetidos a observações pós-operatória durante 15 dias, e os do grupo 2, por 30 dias.

Os cães foram submetidos à administração intravenosa (IV) do antibiótico enrofloxacina $(5,0 \mathrm{mg} / \mathrm{kg})$ e do antinflamatório e analgésico flunixin meglumine $(1,1 \mathrm{mg} / \mathrm{kg}), \quad 30$ minutos antes das intervenções cirúrgicas. Após os procedimentos de rotina de jejum e tricotomia, foram tranquiilizados com maleato de acepromazina $0,2 \%(0,1 \mathrm{mg} / \mathrm{kg}$ IV). A anestesia foi induzida com tiopental sódico 2,5\% (4,0mg/kg IV) e a manutenção anestésica com halotano. A anti-sepsia do campo operatório foi realizada com polivinilpirrolidona.

Realizou-se uma incisão mediana retroumbilical de $4,0 \mathrm{~cm}$ de comprimento para enterectomia de um segmento jejunal de $7,0 \mathrm{~cm}$ de comprimento. $\mathrm{O}$ intestino foi reconstituído através de suturas invaginantes do tipo cushing com categute cromado $n^{\circ} 3-0$. A parede abdominal foi aproximada com pontos em $\mathrm{X}$ utilizando-se categute cromado $\mathrm{n}^{\mathrm{o}} 2-0$, e a pele, com pontos simples separado, utilizando fio de nailon $\mathrm{n}^{\mathrm{o}} 3-0$.

$\mathrm{O}$ segmento intestinal foi evertido e irrigado várias vezes com solução físiológica a $0,9 \%$. Introduziu-se um tubo de ensaio no lume do segmento intestinal evertido e o epitélio e lâmina própria da túnica mucosa foram removidos através de fricções, por meio de uma compressa cirúrgica umedecida em solução fisiológica a $0,9 \%$ (EURIDES et al., 1998). Após lavagens com solução fisiológica $0,9 \%$, o segmento com o tubo de ensaio foi guarnecido na solução anti-séptica 1:1 de solução fisiológica $0,9 \%$ e polivinil-pirrolidona, durante 30 minutos.

Após ser introduzida uma sonda no esôfago, foi praticada uma incisão de pele, caudal à laringe na região mediana ventral do pescoço, de aproximadamente $6,0 \mathrm{~cm}$ de comprimento. Os músculos esternohióideos foram rebatidos lateralmente para exposição do terço médio do esôfago. Com o auxilio de uma lâmina radiográfica estéril de dimensões 3,5 x 3,0cm, demarcou-se uma área do esôfago com quatro pontos de reparo com fio poliglactina $910 \mathrm{n}^{\mathrm{o}}$ 3-0, em cada ângulo. Em 
seguida, foi removido, com o bisturi, por entre os pontos de reparo, um segmento esofágico, resultando num defeito de mesmas dimensões. O segmento intestinal foi retirado da solução antiséptica e irrigado por várias vezes com solução fisiológica a $0,9 \%$, para remoção de um retalho aproximadamente de $3,7 \times 3,2 \mathrm{~cm}$. O enxerto, com a submucosa voltada para o lume esofágico, foi fixado à abertura do esôfago com quatro pontos simples auxiliares, seguido de sutura simples separada com fio poliglactina $910 \mathrm{n}^{\mathrm{o}}$ 3-0 (Figura 1), envolvendo todas as camadas do órgão. $\mathrm{O}$ músculo esternomastóideo foi ancorado ao enxerto com quatro pontos isolados simples e a pele reaproximada com fio de náilon $\mathrm{n}^{\mathrm{o}} 3-0$ em pontos do tipo de Wolff.

Nos cinco primeiros dias de pósoperatório (PO), os cães foram submetidos à administração de enrofloxacina por via subcutânea (SC) na dose de $5,0 \mathrm{mg} / \mathrm{kg}$ duas vezes ao dia, flunecin meglumine $(1,1 \mathrm{mg} / \mathrm{kg}, \mathrm{SC})$ uma vez ao dia por três dias e curativos diários da ferida de pele com solução fisiológica $0,9 \%$ e polivinilpirrolidona. Nas primeiras 48 horas, administrou-se, nos animais, solução glicofisiológica a $5 \%(40 \mathrm{~m} \ell / \mathrm{kg} / \mathrm{dia}, \mathrm{IV})$. No $3^{\circ}$ e $4^{\circ}$ dia, cada animal foi alimentado com uma mistura que continha meio litro de leite, dois ovos e $40 \mathrm{gr}$ de açúcar e água à vontade. A partir do $5^{\circ}$ dia e durante 10 dias, passaram a ingerir ração ${ }^{a}$ umedecida em água, até adquirir a consistência pastosa. Após este período, passaram a ingerir ração granulada e água.

Os pontos de sutura de pele foram retirados decorridos 10 dias de PO. Nos períodos préestabelecidos de $15^{\circ}$ e $30^{\circ}$ dias de $\mathrm{PO}$, os cães foram submetidos a radiografias contrastadas com

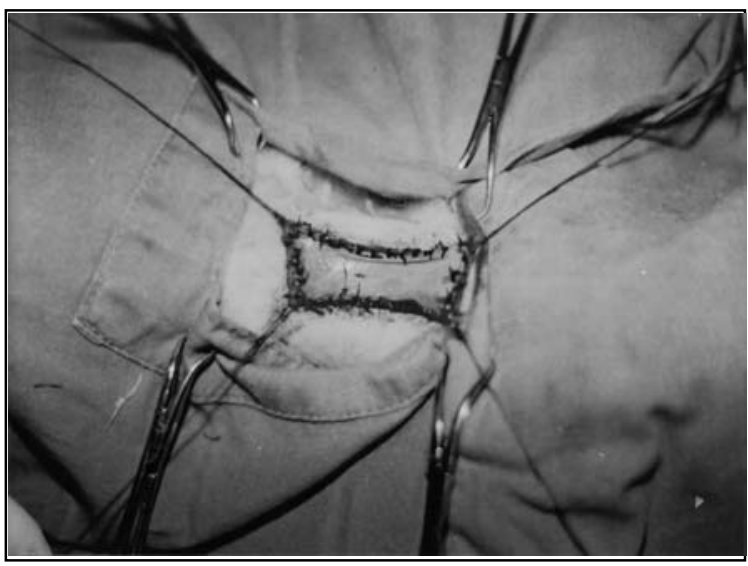

Figura 1 - Esofagoplastia cervical de cão. Fixação do enxerto intestinal, livre e desprovido de epitélio e lâmina própria da túnica mucosa, com pontos simples separado na parede esofágica.

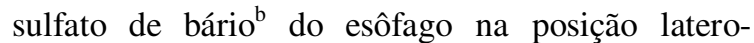
lateral. Após avaliação radiográfica, foram reoperados, para verificar a integridade dos enxertos e coleta de fragmentos de $1 \times 1 \mathrm{~cm}$ da junção enxertoesôfago para avaliação histológica. Os fragmentos foram fixados em formol a $10 \%$ e incluídos em parafina $^{c}$ e os cortes histológicos corados pela técnica Hematoxilina e eosina (HE) e tricrômico de Masson.

\section{RESULTADOS E DISCUSSÃO}

Para substituição de um segmento esofágico de cães, CALIGIURI et al. (1989) e PAVLETIC (1996) recomendaram incluir na sutura interrompida a camada mucosa do esôfago e a submucosa do intestino delgado para obter uma força de suporte ideal. Foi referido por QUESSADA et al. (1986), que a submucosa do esôfago é resistente e que a inclusão da mucosa na síntese é inútil por ser frágil. A inclusão da camada mucosa na sutura esofágica utilizada neste experimento não ocasionou alterações locais.

A sutura simples interrompida que envolve as camadas do intestino e esôfago, empregada nesta pesquisa, foi preferida por evitar o comprometimento do afluxo sangüíneo local (PEACOCK \& VAN WINKLE, 1976), proporcionando boa aproximação do enxerto favorecendo a cicatriazação tecidual.

No reparo do esôfago cervical, não se observou uniformidade quanto ao tipo de fio de sutura empregado, sendo utilizado a seda (CARACHI $\boldsymbol{e}$ t al., 1989) e o categute (DALECK et al., 1988). Nos reparos de defeitos esofágicos de cães com peritônio autólogo ou homólogo, DALECK $\boldsymbol{e t}$ al. (1988) referiram que, decorridos 15 dias o fio categute é absorvido. $\mathrm{O}$ fio poliglactina 910 foi utilizado neste ensaio por ser considerado de baixa reatividade tecidual (SMEAK, 1996) e por apresentar um período de absorção superior a 15 dias, o que, provavelmente, ajudou a manter o enxerto livre firmemente fixo ao esôfago.

A via de acesso ventral ao esôfago utilizada neste trabalho, como sugerida por GIDEON (1984) e QUESSADA et al. (1986), associada à utilização de sonda esofágica (QUESSADA et al. 1986), facilitou a exteriorização do órgão e fixação do enxerto intestinal.

CONTESINI et al. (1992a) e CONTESINI $\boldsymbol{e}$ t al. (1992b) observaram que cães submetidos ao reparo do esôfago cervical apresentavam, nos primeiros dias de pós-operatório regurgitação de alimentos devido à sensibilidade 
dolorosa. Nesta pesquisa, a dieta pós-operatória evitou regurgitação de alimentos e dificuldade de deglutição. Observando-se também que, no final dos 15 dias de dieta pós-operatório, não houve perda aparente do peso corporal dos animais. Por isso, não foi necessária a utilização de sonda esofágica, gastrostomia com sonda e jejunostomia com cateter para alimentar os animais, como recomendado por PAVLETIC (1996).

Ao exame radiográfico, verificou-se discreta estenose no lume esofágico nos cães do grupo 2, coincidente aos achados de PEACOCK \& VAN WINKLE (1976) e DALECK $\boldsymbol{e t}$ al. (1988). A estenose observada não ocasionou dificuldade de deglutição, mesmo quando passaram a ingerir ração granulada, o que está de acordo com os resultados obtidos por DALECK et al. (1988). A diminuição do lume esofágico ocorreu possivelmente devido à retração cicatricial no local do enxerto. Devido à deglutição ter se apresentado aparentemente normal aos aspectos macroscópicos observados, supõe-se que o diâmetro esofágico permaneceu inalterado após o período de observação.

As aderências do músculo esternomastóideo ao enxerto, encontradas em todos os cães, ocorreram devido à ancoragem do enxerto ao músculo com pontos simples separados, fato também observado por CONTESINI et al. (1995), quando utilizou retalho muscular para reparo do esôfago cervical em ovinos. Possivelmente a ancoragem e as aderências notadas contribuíram para vedação da ferida esofágica. DALECK $\boldsymbol{e t}$ al. (1988) notaram que, na reconstituição do esôfago com peritônio de cães, a parede esofágica apresentava-se consistente, com linhas de retração e coloração acinzentada, decorridos 15 dias de PO, sendo os resultados coincidentes aos verificados neste trabalho, possivelmente pela formação de tecido cicatricial (Figura 2). Devido aos aspectos macroscópicos observados, acredita-se que a tensão causada pela sutura em pontos simples separados para aproximação do enxerto não ocasionou prejuízos à circulação local.

Em animais submetidos ao reparo esofágico, HERMRECK \& CRAWFORD (1976) observaram que, nas esofagocoloplastias, houve fístula em $42 \%$ dos casos, e, nas esofagogastroplastias, em 17,8\%. Neste experimento, a ausência de fístulas, abscessos e deiscência dos pontos de sutura, contribuiu para a eficiência do método cirúrgico empregado. Observações semelhantes foram citadas por DALECK et al. (1988) e CONTESINI $\boldsymbol{e t}$ al. (1995), embora tenham utilizado, respectivamente, peritônio

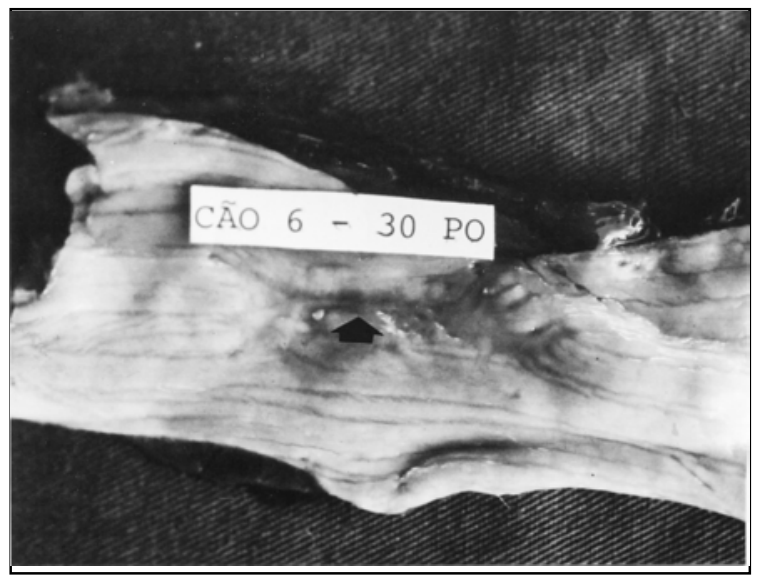

Figura 2 - Aspecto macroscópico do esôfago cervical de cão decorridos 30 dias de pós-operatório da integração enxerto-esôfago. Observa-se a reconstituição da mucosa esofágica, permanecendo apenas uma pequena cicatriz (seta).

de cães e retalho muscular autólogo na reconstituição do esôfago cervical. Entretanto, na utilização de prótese de silicone, CONTESINI et al. (1992a) relataram a ocorrência de fístulas em $20 \%$ dos casos. A ausência de fístulas nos experimentos relatados neste trabalho, deveu-se provavelmente ao controle alimentar durante os 15 primeiros dias de $\mathrm{PO}$, à aproximação esôfago-enxerto com pontos simples separados com fio poliglactina 910, à ancoragem e à aderência do músculo ao esôfago e à perfeita cicatrização tecidual no local do enxerto. Com enxerto autólogo de segmento intestinal livre, ocorreu regeneração parcial do epitélio esofágico com presença de tecido de granulação decorridos 15 dias de pós-operatório. Esses resultados também foram evidenciados por CONTESINI et al. (1992b), porém decorridos 30 dias de PO, com retalho muscular em bovinos. Neste experimento, notou-se epitelização total decorridos 30 dias (Figura 3), com substituição da musculatura lisa do intestino por tecido conjuntivo denso rico em fibras colágenas. Já LAMMERDING et al. (1976), observaram epitelização após dois meses com enxerto diafragmático em esôfago de cães. A regeneração do epitélio esofágico, ocorrida em um período curto de tempo, deveu-se, possivelmente, à ausência de complicações locais.

Decorridos 30 dias do enxerto, notou-se, na parede esofágica, presença de vasos sangüíneos. Esse fato também foi relatado por CONTESINI $\boldsymbol{e t}$ al. (1992b), no $45^{\circ}$ dia de PO na reconstituição do esôfago cervical de bovinos com retalho muscular. A vascularização notada ocorreu devido à reparação cicatricial com substituição da musculatura lisa do segmento intestinal por tecido de granulação rico em fibras colágenas. 


\section{CONCLUSÕES}

Com base nos resultados obtidos nesse experimento, pode-se concluir que:

- o controle alimentar estabelecido nos primeiros 15 dias de pós-operatório da reparação do esôfago com segmento intestinal evita dificuldades de deglutição e regurgitação de alimentos;

- a sutura de aproximação enxerto-esôfago com fio poliglactina 910 em pontos simples separados, envolvendo a mucosa esofágica, fornece boa fixação do segmento intestinal livre ao esôfago;

- o enxerto desprovido de

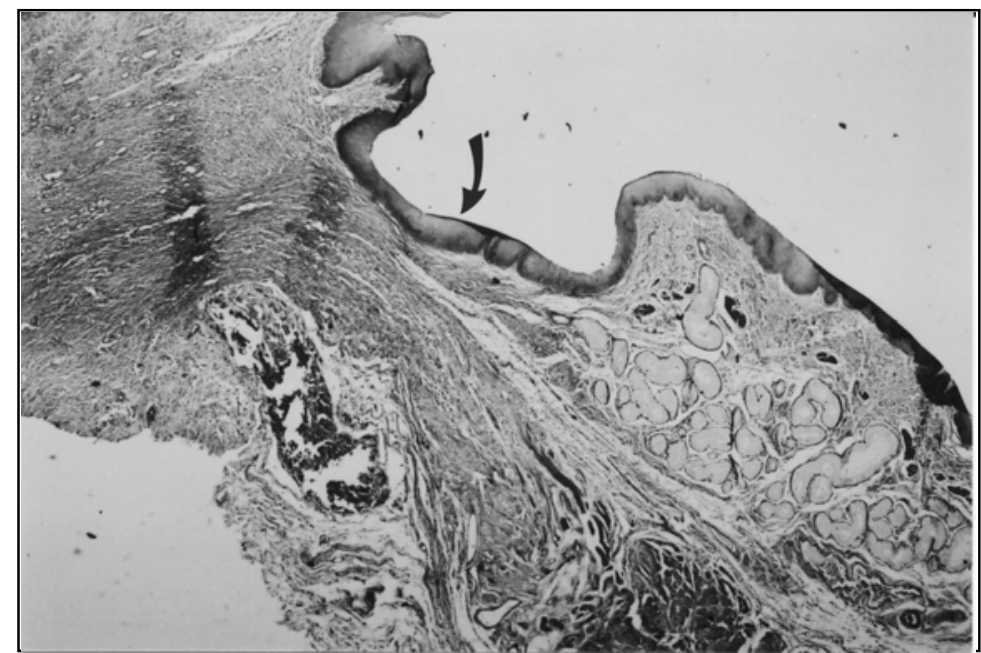

Figura 3 - Aspecto histológico do corte longitudinal da transição esôfago cervicalenxerto de cão decorridos 30 dias de pós-operatorio. Nota-se epitelização da área enxertada (seta), hematoxilina eosina- $38 \mathrm{X}$. vascularização e de epitélio e lâmina própria da túnica mucosa vedou a ferida cirúrgica, servindo como ponte para a proliferação de tecido conjuntivo fibroso, sem complicações pós-operatória, confirmando ser um procedimento cirúrgico adequado.

\section{FONTES DE AQUISIÇÃO}

${ }^{a}$ Ração Kinus. Rações Anhanguera. Campinas, SP.

${ }^{\text {b }}$ Sulfato de Bário. Indústria Guerbet Produtos Radiológicos. Rio de Janeiro, RJ.

${ }^{\mathrm{c}}$ Parafina. Reagean Quimibras Indústria Química. São Paulo, SP.

\section{REFERÊNCIAS BIBLIOGRÁFICAS}

BRIGHT, R.M. Cirurg do esôfago. In: BIRCHARD, S.J., SHERDING, R.C. Manual Saunders. Clínica de pequenos animais. São Paulo : Roca, 1998. p.726-736.

CALIGIURI, R., BELLAH, J.R., COLLINS, B.R., et al. Medical and surgical management of esophageal foreign body in a ferret. Journal of the American Veterinary Medical Association, Schaumburg, v.195, n.7, p.969-971, 1989.

CARACHI, R., AZMY, GORHAM, S., et al. Use of bioprothesis to relieve tension in oesophageal anastomosis an experimental study. British Journal Surgery, Guidford, v.76, p.496-498, 1989.

CHEN H., TANG, Y., NOORDHOFF, M. S. Patch esophagoplasty with musculocutaneus flaps as tratment of complications after esophageal reconstruction. Annals Plastic Surgery, Boston MA, v.19, n.5, p.448-453, 1987.

CONTESINI, E.A, PIPPI, N.L., WITZ, M.I. O uso de tubo de silicone como prótese esofágico cervical em caninos. Ciência Rural, Santa Maria, v.22, n.1, p.57-63, 1992a.
CONTESINI, E.A., PIPPI, N.L., CERVO, H.J., et al. O uso do músculo esternomastóideo como flap na reconstrução parcial da parede esofágica cervical em bovinos. Ciência Rural, Santa Maria, v.22, n.2, p.171-177, 1992b.

CONTESINI, E.A., PIPPI, N.L., NATALINI, C.C., $\boldsymbol{e} \boldsymbol{t} \boldsymbol{a l}$. A restauração da integridade esofágica com o uso de flap muscular sem formação de estenose clínica em ovinos. Ciência Rural, Santa Maria, v. 25, n.3, p.411-416, 1995.

DALECK, C.R., DALECK, C.L.M, GANDOLFI, W., $\boldsymbol{e} \boldsymbol{t} \boldsymbol{a l}$. Esofagoplastia cervical no cão com peritônio autólogo ou homólogo conservado em glicerina - estudo experimental. Ciência Veterinária, Jaboticabal, v.2, n.1, p.1-2, 1988.

EURIDES, D., MAZZANTI, A., BELETTI, M.E., et al. Remoção do epitélio e lâmina própria da túnica mucosa de um segmento intestinal livre de cães. In: CONGRESSO BRASILEIRO DE CIRURGIA E ANESTESIOLOGIA VETERINÁRIA, 3, 1998, Belo Horizonte. Anais... Belo Horizonte : UFMG, 1998. p.95.

FREEMAN, D.E. The alimentar system. In: MANSMANN, R.A., Mc. ALLISTER, E.S. Equine medicine and surgery. 2.ed. Santa Barbara : American Veterinary, 1982. V.1, Cap.13, p.437-644.

FRIEDMAN, D.E., TORIUMI, D.M., CHILIS, T., et al. The sternocleidomastoid myoperiostal flap for esophagopharyngeal reconstruction and fistula repair: clinical and experimental study. Laryngoscope, ST. Louis, v. 98, p. 1084-1091, 1988

GIDEON, L. Esophageal anatomosis in two foals. Journal of the American Medical Association, Schaumburg, v.184, n.9, p.1146-1148, 1984.

HAMNER, J.M., SEAY, P.H., HILL, E.J., et al. Intetinal segments as internal pedicucle grafts. Archives Surgery. v.71, p.625-642, 1955 .

HERMRECK, AS., CRAWFORD, D.G. The esophageal anastomotic leak. American Medicine Journal Surgery, New York, v.132, p.794-798. 1976. 
HOFFER, R.E. Esophagus: surgical diseases. In: SLATTER, D. Textobook small. animal surgery. Philadelphia : Saunders, 1985. 2v. V.1. Cap.48, p.654-679.

LAMMERDING, J., HOWARD, D.R., NOSER, G.A. Diaphragmatic pedicle flaps for repair of distal esophageal defects in dogs. Journal of American Animal Hospital Association, Kansas, v.12, n.1, p.588-592, 1976.

LYONS, A.S., BECK, AR., LESTER, L.J. Esophageal replacement with prothesis. Journal of Surgical Research, New York, v.2, n.2, p.110-113, 1962.

NIGRO, A.J.T. Anastomoses esôfago-esofagicas cervical por invaginação. Estudo experimental em cães. Acta Veterinária Brasileira, São Paulo, v.11, n.2, p.63-75, 1996.

PARKER, N.R., CAYWOOD, D.D. Surgical diseases of the esophagus. Veterinary Clinics of North America: Small Animal Practice, Orlando, v.17, n.2, p.333-358, 1987.

PAVLETIC, M.M. Técnicas de reconstituição esofágica. In:
BOJRAB, M.J. Técnicas atuais em cirurgia de pequenos animais. 3.ed. São Paul o: Roca, 1996. Cap.13, p.196203.

PEACOCK, E.E., VAN WINKLE, W. The surgery and biology of wound repair. 2.ed. Philadelphia : Saunders 1976. Cap.12: Healing and repair of viscera: p.609-681.

QUESSADA, A.M., SANTOS, R.S., BERNIS, W.O., et al. Esofagotomia cervical no cão- observações sobre a sutura em plano único. Revista Brasileira de Medicina Veterinária, Rio de Janeiro, v.8, n.4, p.117-120, 1986.

SMEAK, D.D. Escolha e uso dos materiais de sutura atualmente disponíveis. In: BOJRAB, M.J. Técnicas atuais de cirurgia de pequenos animais. 3. ed. São Paulo : Roca, 1996. Cap.3. p.33-38.

ZILBERSTEIN, B., NASI, A, PINHEIRO, E.A, et al. Autotransplante de intestino delgado em substituição ao esôfago cervical - indicação, técnica e experiência clínica. Revista Hospital de Clínicas da Faculdade de Medicina de São Paulo, v.42, n.1, p.21-25, 1987. 